\title{
SOME APPLICATIONS OF SCHWARZ LEMMA FOR OPERATORS
}

\section{AKSHAYA KUMAR MISHRA}

\author{
School of Mathematical Sciences \\ Sambalpur University \\ Jyoti Vihar 768019 , Orissa \\ India
}

(Received March 16, 1987)

ABSTRACT. A generalized Schwarz lemma and some Harnack type inequalities for operators have been obtained in this paper.

KEY WORDS AND PHRASES. Operator, Proper Contraction, Schwarz lemma, Harnack's Inequalities.

1980 MATHEMATICS SUBJECT CLASSIFICATION CODE. 47A 60.

1. INTRODUCTION.

Let $\mathrm{A}$ be a bounded linear operator on a complex Hilbert space $\mathrm{H}$. For a complex valued function $f$ analytic on a domain $E$ of the complex plane containing the spectrum $\sigma(A)$ of $A$, let $f(A)$ denote the operator on $H$ defined by the Riesz Dunford integral $([2$, p. 568 $])$.

$$
f(A)=\frac{1}{2 \pi i} \int_{C} f(z)(z I-A)^{-1} d z,
$$

where $C$ is a postively oriented simple closed rectifiable contour containing $\sigma(A)$ in its inside domain $\Omega$ and satisfying CU $\Omega$ E.Fan[3] has obtained Schwarz lemma for $f(A)$ and has given several applications of his results including the Harnack's inequalities for operators in $[3,4]$.

In this paper, we obtain a generalized Schwarz lemma and some further Harnack type inequalities for operators.

2. SOME PRELIMINARY LEMMAS.

We need the following lemmas.

LEMMA 1. Let $a, b, c, d$ be complex numbers such that ad - bc $\neq 0, c \neq 0$ and let $\mathrm{T}$ be a bounded linear operator on a Hilbert space $\mathrm{H}$ such that $-\mathrm{d} / \mathrm{c}$ is not in $\sigma(\mathrm{T})$. Then

$$
\left\|(a T+b I)(c T+d I)^{-1}\right\| \leqq r
$$

for $0<\mathrm{r}<\mid$ a $|\mathrm{c}|$ if and only if 


$$
\left\|T+\frac{\overline{a b}-r^{2} \overline{c d}}{|a|^{2}-r^{2}|c|^{2}} I\right\| \leqq \frac{r|a d-b c|}{|a|^{2}-r^{2}|c|^{2}}
$$

Equality holds in (2.1) and (2.2) simultaneously.

PROOF. The inequality (2.1) is true if and only if

$$
\mathrm{r}^{2} \mathrm{I}-\left(\overline{\mathrm{c}} \mathrm{T}^{*}+\overline{\mathrm{d}} \mathrm{I}\right)^{-1}\left(\overline{\mathrm{a}} \mathrm{T}^{*}+\overline{\mathrm{b}} \mathrm{I}\right)(\mathrm{aT}+\mathrm{bI})(\mathrm{cT}+\mathrm{dI})^{-1} \geqq 0
$$

or

$$
\left(\bar{c} T^{*}+\bar{d} I\right)^{-1}\left[r^{2}\left(\bar{c} T^{*}+\bar{d} I\right)(c T+d I)-\left(\bar{a} T^{*}-\overline{b I}\right)(a T+b I)\right](c T+d I)^{-1} \geqq 0
$$

The operator inside the square brackets can be written as

$$
\frac{r^{2}|a d-b c|}{|a|^{2}-r^{2}|c|^{2}} I-\left\{T^{*} T+\frac{\overline{a b}-r^{2} \overline{c d}}{|a|^{2}-r^{2}|c|^{2}} T * \frac{a \bar{b}-r^{2} c \bar{d}}{|a|^{2}-r^{2}|c|^{2}} T+\frac{\left|\bar{a} b-r^{2} \bar{c} d\right|^{2}}{\left(|a|^{2}-r^{2}|c|^{2}\right)^{2}} I\right\}
$$

or

$$
\frac{r^{2}|a d-b c|}{|a|^{2}-r^{2}|c|^{2}} I-\left[T^{*}+\frac{a \bar{b}-r^{2} c \bar{d}}{|a|^{2}-r^{2}|c|^{2}} I\right] \quad\left[T+\frac{\bar{a} b-r^{2} \overline{c d}}{|a|^{2}-r^{2}|c|^{2}} I\right] \text {. }
$$

This last expression is a positive operator if and only if (2.2) holds. This completes the proof.

LEMMA 2. Let $a, b, c, d$ and $T$ be as in Lemma 1 . Then,

$$
\left\|(a T+b I)(c T+d I)^{-1}-\frac{b \bar{d}-r^{2} a \bar{c}}{|d|^{2}-r^{2}|c|^{2}} I\right\| \leqq \frac{r|a d-b c|}{|d|^{2}-r^{2}|c|^{2}}
$$

for $0<r<|d| /|c|$ if and only if $\|T\| \leqq r$. Equality holds in (2.3) if and only if $\|T\|=r$.

PROOF. The inequality (2.3) is equivalent to $\left\|\left\{(a T+b I)\left(|d|^{2}-r^{2}|c|^{2}\right)-\left(b \bar{d}-r^{2} a \bar{c}\right)(c T+d I)\right\}(c T+d I)^{-1}\right\| \leq r|a d-b c|-$ After simplication the above can be written as

$$
\left\|\left(\overline{\mathrm{d}} \mathrm{T}+\mathrm{r}^{2} \overline{\mathrm{c}} \mathrm{I}\right)(\mathrm{cT}+\mathrm{dI})^{-1}\right\| \leqq \mathrm{r} .
$$

Now an application of Lemma 1 shows that $(2.4)$ is equivalent to $\|\mathrm{T}\| \leqq \mathrm{r}$.

3. A GENERALIZED SCHWARZ LEMMA.

Let $D$ denote the open unit disc $\{z:|z|<1\}$ in the complex plane and let $H(D)$ be the class of complex valued functions analytic in $D$. Further, let $B(D)=\{f \in H(D):|f(z)|<1, z \in D\}$ and let $B_{O}(D)=\{f \in B(D): f(0)=0\}$. 
THEOREM 1. Let $\mathrm{f}$ be in $\mathrm{B}(0)$ and let $\mathrm{A}$ be a proper contraction on a Hilbert space H. Then,

$$
\frac{\|A\|-|f(0)|}{1-|f(0)|\|A\|} \leqq\|f(A)\| \leqq \frac{\|A\|+|f(0)|}{1+|f(0)|\|A\|} .
$$

PROOF. Since $f$ is in $B(D)$ and $A$ is a proper contraction, by a result of $F$ and ([3, Theorem 1, p.276]), $T=f(A)$ is also a proper contraction. Now, if we define the complex valued function $g$ by $g(z)=(f(z)-f(0))(1-\overline{f(0)} f(z))^{-1}$ then $g$ is in $B_{0}(D)$ and $g(A)=(T-f(0) I)(I-\overline{f(0)} T)^{-1}$ is also a proper contraction. Further, by the operator version of Schwarz lemma ([3, Corollary 2, p.280]),

$$
\|g(A)\| \leqq\|A\|
$$

If we take $a=d=1, b=f(0), c=-\overline{f(0)}$ and $r=\|A\|$ in Lemma 1 then (3.2) is equivalent to

$$
\left\|f(A)-\frac{1-\|A\|^{2} f(0)}{1-|f(0)|^{2}\|A\|^{2}} \quad I\right\| \leqq \frac{\left(1-|f(0)|^{2}\right)\|A\|}{1-|f(0)|^{2}\|A\|^{2}} .
$$

Using triangle inequality we get both the inequalities in (3.1).

CORALLARY 1. Let $f$ in $B_{0}(D)$ be given by the series $f(z)=b z^{n}+\ldots \ldots \ldots$, $b \neq 0$, and let $A$ be a proper contraction on a Hilbert space $H$. Then

$$
\left\|A^{n}\right\|\left(\frac{\|A\|-|b|}{1-|b|\|A\|}\right) \leqq\|f(A)\| \leqq\left\|A^{n}\right\|\left(\frac{\|A\|+|b|}{1+|b|\|A\|}\right) \text {. }
$$

PROOF. The function $g$, defined by $g(z)=\left(f(z) / z^{n}\right), z \neq 0$ and $g(0)=b$, is in $B(D)$ and $f(A)=A^{n} g(A)$. Hence the result follows from Theorem 1 .

REMARK. The author learned from Professor R. Finn that Theorem 1 follows independently from some results of $\mathrm{K}$. Fan that are now in press.

\section{SOME HARNACK TYPE INEQUALITIES.}

Let $P(\alpha, \beta), 0 \leqq \alpha<1,0<\beta \leqq 1$, denote the subclass of functions $p$ in $H(D)$ satisfying $p(0)=1$ and

$$
\frac{|p(z)-1|}{|(2 \beta-1) p(z)+(1-2 \alpha \beta)|}<1, z \text { in } D
$$

This class of functions have been introduced and studied by Juneja and Mogra [5]. It has been shown in [5] that the $n^{\text {th }}$ Taylor coefficient $a_{n}$ of a function $p$ in $P(\alpha, \beta)$ satisfies the sharp inequality $\left|a_{n}\right| \leqq 2 \beta(1-\alpha)$. Observe that

$$
\begin{aligned}
& P(0,1)=\left\{\begin{array}{ll}
\mathrm{p} \varepsilon & H(D): p(0)=1, \operatorname{Re} p(z)>0, z \text { in } D
\end{array}\right\} \\
& P(\alpha, 1)=\{p \varepsilon \quad H(D): p(0)=1, \operatorname{Re} p(z)>\alpha, z \text { in } D\}, \\
& P(0, \beta)=\left\{p \varepsilon \quad H(D): p(0)=1, \mid p(>)-\frac{1}{2(1-\beta)}<\frac{1}{2(1-\beta)}\right\},
\end{aligned}
$$


and

$P(\alpha, \beta) \subset P(0,1)$, for all admissible choices of $\alpha$ and $\beta$. We prove the following theorem which extends a distortion theorem by Kapoor and the author ([6, Theorem 1, p. 86]).

THEOREM 2. Let $p$ in $P(\alpha, \beta)$ be given by the series $p(z)=1+2 b(1-\alpha) \beta z^{a}+\ldots$, $0<|b| \leqq 1, z$ in $D$ and let $A$ be a proper contraction on a Hilbert space $H$. Then,

$$
\begin{aligned}
& \|\mathrm{p}(\mathrm{A})\| \leqq \frac{1+\|\mathrm{A}\||\mathrm{b}|+(1-2 \alpha \beta)(\|\mathrm{A}\|+|\mathrm{b}|)\left\|\mathrm{A}^{\mathrm{n}}\right\|}{1+\|\mathrm{A}\||\mathrm{b}|+(1-2 \beta)(\|\mathrm{A}\|+|\mathrm{b}|)\left\|\mathrm{A}^{\mathrm{n}}\right\|} \text {, } \\
& \|P(A)\| \geqq \frac{1+\|A\||b|-(1-2 \alpha \beta)(\|A\|+|b|)\left\|A^{n}\right\|}{1+\|A\||b|-(1-2 \beta)(\|A\|+|b|)\left\|A^{n}\right\|}, \\
& 1+\|A\||b|-(1-2 \alpha \beta)(\|A\|+|b|)\left\|A^{n}\right\| \\
& \overline{1+\|A\||b|-(1-2 \beta)(\|A\|+|b|)\left\|A^{n}\right\|} I \leqq \operatorname{Re} p(A) \text {, } \\
& \operatorname{Re} p(A) \leqq \frac{1+\|A\||b|+(1-2 \alpha \beta)(\|A\|+|b|)\left\|A^{n}\right\|}{1+\|A\||b|+(1-2 \beta)(\|A\|+|b|)\left\|A^{n}\right\|} I, \\
& \pm \operatorname{Im} p(A) \leqq \frac{2 \beta(1-\alpha)(\|A\|+|b|)(1+\|A\||b|)\left\|A^{n}\right\|}{(1+\|A\||b|)^{2}-(1-2 \beta)^{2}(\|A\|+|b|)\left\|A^{n}\right\|^{2}} I .
\end{aligned}
$$

PROOF. From the definition of $P(\alpha, \beta)$, it follows that there exists a function $w$ in $B_{0}(D)$ such that

$$
\mathrm{p}(\mathrm{z})=\{1+(1-2 \alpha \beta) \mathrm{w}(\mathrm{z})\}\{1+(1-2 \beta) \mathrm{w}(\mathrm{z})\}^{-1}, \mathrm{z} \text { in } \mathrm{D}
$$

and

$$
\mathrm{p}(\mathrm{A})=\{1+(1-2 \alpha \beta) \mathrm{T}\}\{1+(1-2 \beta) \mathrm{T}\}^{-1} \text {, where } \mathrm{T}=\mathrm{w}(\mathrm{A}) .
$$

Further, it is observed that $w(z)=b z^{n}+\ldots .$. , where $z$ in $D$. Hence by Corollary 1 ., we can say

$$
\|\mathrm{T}\|=\|\mathrm{w}(\mathrm{A})\| \leqq\left\|\mathrm{A}^{\mathrm{n}}\right\|\left(\frac{\|\mathrm{A}\|+|\mathrm{b}|}{1+\|\mathrm{A}\||\mathrm{b}|}\right)=\mathrm{r} \text {. }
$$

Now, choosing $a=1-2 \alpha \beta, c=1-2 \beta, b=d-1$ in Lemma $2,(4.6)$ is equivalent to

$$
\left\|p(A)-\frac{1-r^{2}(1-2 \alpha \beta)(1-2 \beta)}{1-r^{2}(1-2 \beta)^{2}}\right\| \leqq \frac{2 r(1-\alpha) \beta}{1-r^{2}(1-2 \beta)^{2}} .
$$

Hence

$$
\frac{1-(1-2 \alpha \beta) \mathrm{r}}{1-(1-2 \beta) \mathrm{r}} \leqq\|\mathrm{p}(\mathrm{A})\| \leqq \frac{2+(1-2 \alpha \beta) \mathrm{r}}{(1-\alpha) \mathrm{r}} \text {. }
$$


Substituting the value of $r$ in the above inequality, we get (4.1) and 4.2). Also,

$$
\begin{aligned}
& \pm \operatorname{Re}\left[\mathrm{p}(\mathrm{A})-\frac{1-\mathrm{r}^{2}(1-2 \alpha \beta)(1-2 \beta)}{1-(1-2 \beta)^{2} \mathrm{r}^{2}} \mathrm{I}\right] \leqq\left\|\mathrm{p}(A)-\frac{1-\mathrm{r}^{2}(1-2 \alpha \beta)(1-2 \beta)}{1-\mathrm{r}^{2}(1-2 \beta)^{2}} I\right\| I \\
& \leq \frac{2 r(1-\alpha)^{\beta}}{1-\mathrm{r}^{2}(1-2 \beta)^{2}} I .
\end{aligned}
$$

This gives (4.3) and (4.4). Similarly,

$$
\begin{aligned}
\pm \operatorname{Im} p(A) & = \pm \operatorname{Im}\left[\mathrm{p}(A)-\frac{1-\mathrm{r}^{2}(1-2 \alpha \beta)(1-2 \beta)}{1-\mathrm{r}^{2}(1-2 \beta)^{2}} I\right] \\
& \leqq\left\|\mathrm{p}(A)-\frac{1-\mathrm{r}^{2}(1-2 \alpha \beta)(1-2 \beta)}{1-\mathrm{r}^{2}(1-2 \beta)^{2}} I\right\| I \leqq \frac{2 \beta(1-\alpha) r}{1-\mathrm{r}^{2}(1-2 \beta)^{2}} I .
\end{aligned}
$$

From this (4.5) follows. This completes the proof.

REMARK. The right hand side of (4.1) and (4.2) are increasing and decreasing function of $|b|$, respective $1 y$. For the case $|b|=1, \alpha=0$ and $\beta=1$, our Theorem 2 includes some results of Fan ([3, Corollary 3,P281], [4, Proposition 2,P.335]).

ACKNOWLEDGEMENT. The author wishes to thank Professor R. Finn for his useful suggestions.

\section{REFERENCES}

1. CARATHEODORY, C. Theory of functions of a complex variable, Vol.II, Chelsea Publishing Company, New York, 1954.

2. DUNFORD, N. and SCHWARTZ, J.T. Linear Operators, Part I, General Theory, New York, Interscience, 1958.

3. FAN, KY. Analytic functions of a proper contraction, Math. Z. 160 (1978), 275-290.

4. FAN, KY. Harnack's inequalities for operators, General Inequalities 2, Edited by E.F. Beckenbach, Birkhauser Verlarg, Basel, 1980.

5. JUNEJA, O.P. and MOGRA, M.L. Radius of convexity for certain classes of analytic functions, Pacific J. Math. 78 (1978), 359-368.

6. KAPOOR, G.P. and MISHRA, A.K. Distortion theorems for some rlassc, analytic functions, Houston J. Math. $\underline{8}$ (1982), 85-92. 


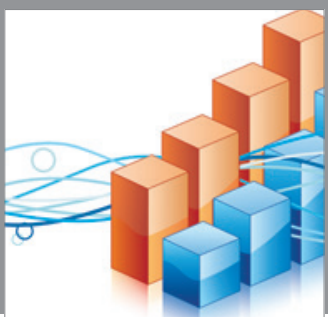

Advances in

Operations Research

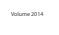

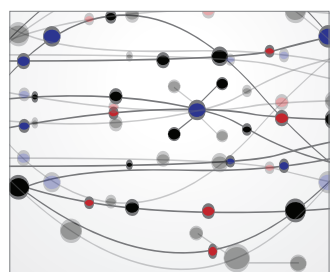

\section{The Scientific} World Journal
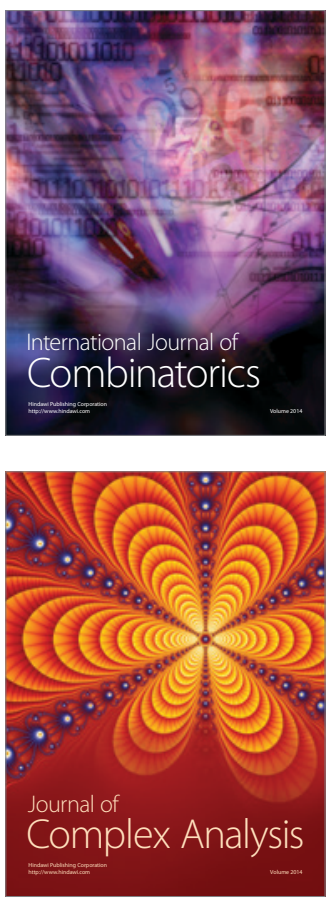

International Journal of

Mathematics and

Mathematical

Sciences
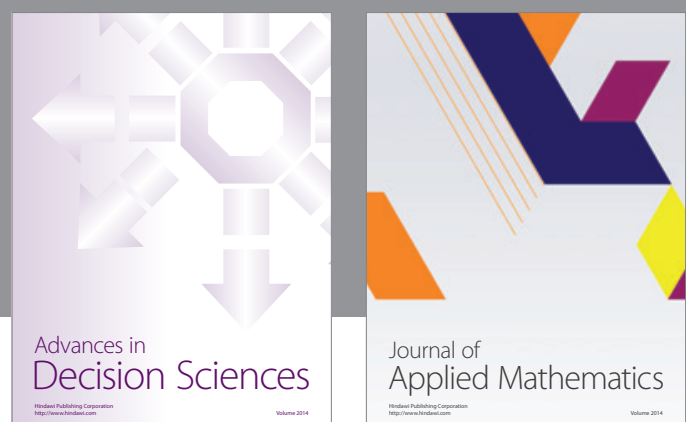

Journal of

Applied Mathematics
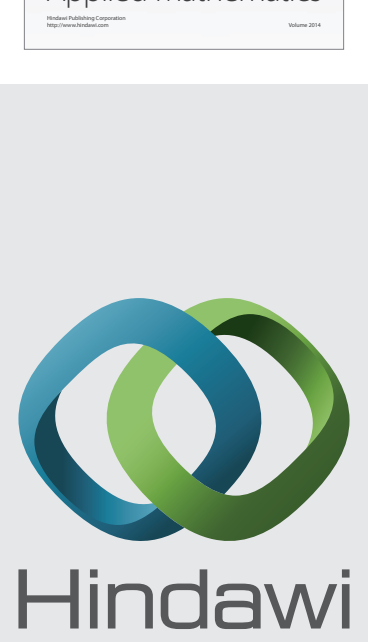

Submit your manuscripts at http://www.hindawi.com
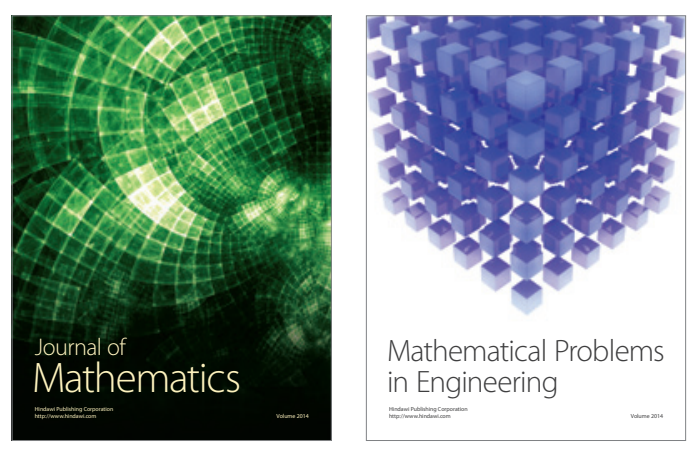

Mathematical Problems in Engineering
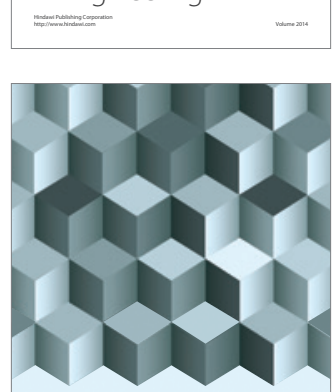

Journal of

Function Spaces
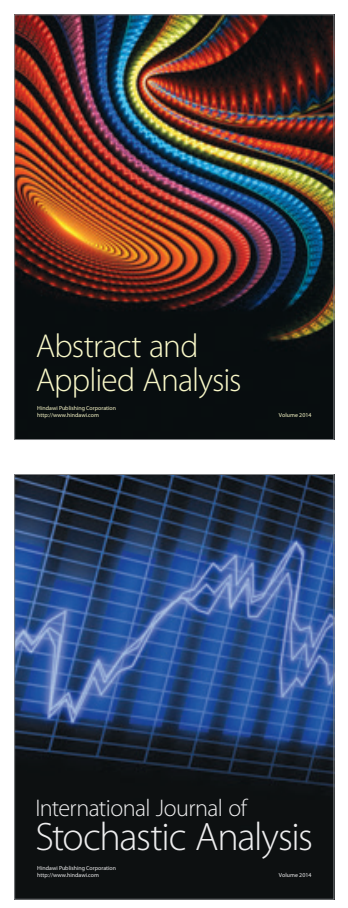

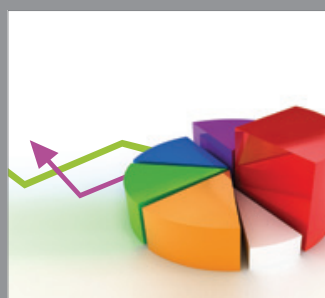

ournal of

Probability and Statistics

Promensencen
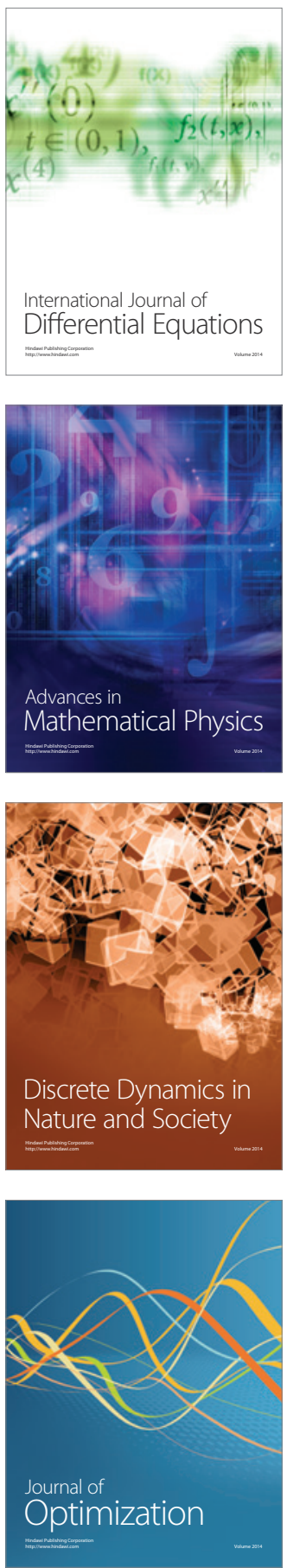